\title{
Patient safety in care circumstances: prevention of adverse events in the hospitalization of children ${ }^{1}$
}

\author{
Wiliam Wegner ${ }^{2}$ \\ Eva Neri Rubim Pedro ${ }^{3}$
}

This case study with a qualitative approach presents an analysis of the perceptions of family caregivers/companions and health workers concerning adverse events in care contexts. A total of 15 companions and 23 health workers from pediatric hospitalization units of a university hospital in Porto Alegre, Brazil participated in this study from August to December 2010. Data were collected through semi-structured interviews and analyzed through thematic content analysis using QSR's Nvivo version 7.0. Seven thematic categories emerged from the analysis. The results highlight reviewing and checking workers' interventions and implementing effective communication among workers, caregivers and children. The main recommendations concern changing the organizational culture of health facilities, emphasizing safe care and a systemic view of the evaluation of adverse events.

Descriptors: Safety; Hospitalized Child; Medical Errors; Caregivers; Health Personnel.

\footnotetext{
${ }^{1}$ Paper extracted from Doctoral Dissertation "A segurança do paciente nas circunstâncias de cuidado: prevenção de eventos adversos na hospitalização infantil", presented to Escola de Enfermagem, Universidade Federal do Rio Grande do Sul, Brazil.

${ }^{2}$ PhD, Full Professor, Centro Universitário Metodista IPA, Brazil.

${ }^{3}$ PhD, Associate Professor, Escola de Enfermagem, Universidade Federal do Rio Grande do Sul, Brazil.
} 


\title{
A segurança do paciente nas circunstâncias de cuidado: prevenção de eventos adversos na hospitalização infantil
}

Trata-se de pesquisa de abordagem qualitativa do tipo estudo de caso, cujo objetivo foi analisar como as acompanhantes/cuidadoras e profissionais da saúde reconhecem os eventos adversos nas circunstâncias de cuidado. Foi realizada com 15 acompanhantes/cuidadores e 23 profissionais da saúde das unidades de internação pediátrica de um hospital-escola de Porto Alegre, RS, Brasil, no período entre agosto e dezembro de 2010. A entrevista semiestruturada foi utilizada na coleta das informações, sendo submetida à técnica da análise temática com apoio do software QSR Nvivo, versão 7.0. A análise das informações evidenciou sete categorias temáticas. Nos resultados, destacam-se a revisão e conferência permanentes em qualquer intervenção do profissional e o processo de comunicação efetivo profissional/acompanhante/ criança. O estudo traz como principais recomendações as mudanças na cultura organizacional das instituições de saúde para uma cultura de segurança, com ênfase no cuidado seguro em saúde e visão sistêmica na avaliação da ocorrência de eventos adversos.

Descritores: Segurança; Criança Hospitalizada; Erros Médicos; Cuidadores; Profissionais da Saúde.

\section{La seguridad del paciente en las circunstancias de cuidado: prevención de eventos adversos en la hospitalización infantil}

\begin{abstract}
Se trata de una investigación estudio de caso cualitativo, cuyo objetivo fue analizar cómo las acompañantes/cuidadoras y profesionales de salud reconocen los eventos adversos en las circunstancias de cuidado. Fue realizada con 15 acompañantes/cuidadores y 23 profesionales de salud de las unidades de internación de pediatría de un hospital-escuela de Porto Alegre, Brasil entre agosto y diciembre de 2010. Entrevista semi-estructurada fue utilizada para la recolección de las informaciones, siendo sometidas a análisis temático con apoyo del software QSR Nvivo 7.0. El análisis de las informaciones dejó en evidencia siete categorías. Los resultados sugieren la revisión y control permanente en cualquier intervención del profesional y el proceso de comunicación efectivo profesional-acompañante-niño. El estudio trae como recomendaciones los cambios en la cultura organizacional de las instituciones de salud para una cultura de seguridad, con énfasis en el cuidado seguro y visión sintética en la evaluación de la ocurrencia de eventos adversos.
\end{abstract}

Descriptores: Seguridad; Niño Hospitalizado; Errores Médicos; Cuidadores; Personal de Salud.

\section{Introduction}

Health care delivery involves a number of circumstances that may compromise the safety of children and their companions. Adverse events highlight issues in health care services, which are seldom discussed and put into context - because it is a difficult subject to address - and are often approached only in an indirect manner by professionals and even by the health services' users.

Health care circumstances related to adverse events that culminate in errors are acknowledged in the literature and in daily practice. Such errors are responsible for millions of deaths around the world. The World Alliance for Patient Safety was created in 2004 by the World Health Organization (WHO) with the main objective to mobilize global effort toward the delivery of safe health care to all patients ${ }^{(1)}$.

Patient safety means to reduce unnecessary risks to the minimum possible level while providing health care. Such a strategy is designed to avoid, prevent, and minimize outcomes of adverse events arising in health care practices ${ }^{(2-3)}$. Adverse events include harm accruing from care provided by health workers not related to the patient's primary disease. These events may 
prolong hospitalization or change the treatment initially proposed $^{(2-4)}$.

The omission of errors per se is a situation that involves various, mediate and immediate consequences with the potential to compromise patient treatment. Professional experience in the context of pediatric care shows such errors do happen in healthcare practice and are not uncommon; it is easier to forget or deny the fact than it is to take responsibility for actions that did not develop as planned. When the possibility of errors occurring is acknowledged, sterile criticism concerning the individual personalization of adverse events is minimized.

One study performed by the World Alliance for Patient Safety reports that between $3 \%$ and $16 \%$ of patients suffer adverse events due to unsafe medical care provided during hospitalization. The scope of these circumstances was verified in all studied countries, whether they were developed, developing or underdeveloped nations, though most data originate from developed nations. It is believed that such results are far worse and with less positive prospects in poor nations ${ }^{(5)}$.

The study's guiding question is: How and why do healthcare circumstances expose hospitalized children to adverse events, compromising their safety and protection?

This study's thesis is that care circumstances predispose the hospitalized child to adverse events in health care settings, interfering in patient safety.

In this study, care circumstances refer to actions performed by or for someone in the context of health care that characterize care and interventions performed by health workers. This conception was proposed and characterized in healthcare delivery beyond specific technical procedures and interventions. It was enlarged to encompass the relationships, routines, planning of institutional development and strategic planning, aiming for a systemic and procedural view of all the elements that constitute the relationship of care delivery. Care circumstances involve the action per se (intervention, procedure, conduct), the staff (health workers), the patient (child, companion, or family), the context (work processes, corporations, rules/standards, hospital-centered culture) and the setting (hospital, hospitalization unit). The elements comprising care circumstances should contribute to and positively influence safe healthcare delivery but there are asynchronisms/deviations that result in errors in this systemic framework that is patient safety(6).

This study's general objective was to analyze how family caregivers/companions and health workers perceive adverse events in the context of care circumstances.

\section{Method}

This is an exploratory case study and the theoretical/ methodological approach used was qualitative. The case study design refers to the systematic analysis of multiple forms of information that enable one to understand a given context and people in such a context. It enables one to preserve the meaningful, holistic and integral characteristics of real life events when the boundaries between the phenomenon and context are not clearly defined ${ }^{(7)}$. The unit of analysis was the care circumstances present in the context of children hospitalized in a health care facility.

The study was developed in the Hospital de Clínicas in Porto Alegre, RS, Brazil in the following pediatric hospitalization units: $10^{\text {th }}$ North, $10^{\text {th }}$ South, and $3^{\text {rd }}$ East. The studied units have 96 beds together designated for heath care delivered to children with the most varied conditions.

The study's participants were 23 health workers from the selected services and 15 companions. The selection of all the participants was intentional. The nurses of each shift helped to indicate potential participants. Data were collected from August to December 2010.

Data were collected through semi-structured interviews. Two scripts containing the guiding questions were developed. The scripts were based on the study questions, which were directed to the companions and health workers involved in care circumstances, aiming to understand the studied phenomenon. Data generated at this stage were transcribed and analyzed through thematic content analysis( ${ }^{(8)}$. QSR Nvivo version 7.0 was used to organize the information.

Bioethical principles were complied with in accordance with Resolution 196/96. The project was submitted to and approved by the Scientific Committee and Ethics Research Committee at the Hospital de Clínicas in Porto Alegre, RS, Brazil (protocol No. 100085) before data collection was initiated. The participants were informed that participation was voluntary and they could withdraw from the study at any time without, however, incurring any cost or harm to themselves or the child under treatment, or interference in the activities of the involved professionals. Free and informed consent forms were signed. The information provided by the companions was codified by the letter $\mathrm{C}$ followed by a number to indicate the order of participation, i.e., $\mathrm{C} 1=$ companion 1 . The workers' reports were codified by the letter $\mathrm{W}$, i.e., $\mathrm{W} 5=$ Worker 5 .

\section{Results}

Seven thematic categories emerged from the analysis and interpretation process. The categories were 
developed to confirm and support the study's thesis. The first three were constructed based on the empirical material collected from the companions.

The study included 38 participants, 15 of whom were companions of the hospitalized children and 23 were health workers. The children's companions were mainly mothers of low socio-economic status, who experienced inequalities related to education, access to basic services, and to the job market. In regard to the hospitalized children, their peculiarities reveal they may be constant users of health services with a great predisposition to problems related to growth and development, given their chronic disease condition and the contextual issues of their families. The health workers proved to compose an experienced team, mature and qualified to care for the hospitalized children.

The first category was named adverse events in the care circumstances identified by the hospitalized child's companion. It describes the main failures identified by the mothers during their children's hospitalizations. A greater concern is observed concerning medication, which has the potential to impede one's recovery and also aggravate one's health condition. The following report exemplifies such a concern:

She [technician] gave my daughter worm medication but did not make a note in her file, then the other worker arrived to assume the shift and gave the same medication again. The one who gave the medication the second time is not the one to blame, but the one who didn't make the note. I noted her name to make a complaint (C12).

The companions also considered the following to be adverse events: poor communication, inaccurate medical diagnosis, invasive procedures, the fact children become worsened after procedures, superficial physical assessments, contamination of children through workers, insufficient staff, incorrect identification of children, the fact that companions perform care actions that are actually within the competence and responsibility of health workers, exhaustion/tiredness of the children's companions.

The second category, safe health care from the perspective of the hospitalized child's companion, listed strategies to provide safe health care. Soft technologies have been a central element in the field of health care but soft-hard technologies complement and strengthen patient safety. The intents of health workers allied with effective communication are essential to the quality of care provided to hospitalized children. Similarly, individual care, access to and understanding of information concerning the child's health condition, the implementation of interventions in a quality manner and punctually, rigorous hand washing and sterilization of equipment, teamwork with a critical view, and good sense, permeate the delivery of safe health care in the opinion of the companions. This participant contextualizes an effective communication process:

The nurses, physicians, the entire staff is very attentive, I have nothing to complain about and anything we need, they are attentive to answer, clarify our questions, whatever we need (C5).

The third category, the role of companions in the safety of hospitalized children, delineates the responsibilities that should be assigned to companions, highlighting supervision and monitoring of care delivery as their main role. Sharing primary care, such as providing hygiene or comfort and feeding the child under the supervision and guidance of the nursing staff, is a demand of mothers who want to become involved with and participate in the care provided to their children, but the nursing staff cannot be replaced or exempted from such responsibilities. One mother stresses that supervision is the main role of a family caregiver accompanying the child during hospitalization.

Supervision. I supervise all the time, I observe, what are you putting there? What is the medication you're going to give now? But, why? - Because it's happened many times, the person comes here and does a procedure wrong, I can see it's wrong, it's been said it'd be done differently... look, this is wrong! But, why? The other one didn't do it this way [...] and it's not the way I'm going to do it, so I say, no, go there and get informed (C4).

The ability to observe, protect and support their children and being inquisitive are pro-active attitudes of mothers in the process of communication with workers. The presence of a companion/caregiver was considered a requirement in the development of a patient safetyoriented culture in the context of child hospitalization because of all these roles identified.

The fourth category, hospital: is it a safety setting for children?, questions the need for hospitalization and indications for the child to be referred to this care setting. The presence of a multidisciplinary staff and the interdisciplinary work developed by it make the hospital a safe environment to provide health care. The following worker highlights the multidisciplinary staff and the concern of the hospital with patient safety:

Yes, I consider it to be safe. Despite the fact it is safe, things may happen and compromise the safety of patients, but most of time it is safe due to its professionals [...] we try to be very attentive with the patients so errors do not occur, but still they may occur (W13).

The fifth category adverse events from the perspective of health workers describes the main circumstances leading to the occurrence of errors in the health care provided to hospitalized children. The participants initially elaborated a conception of what an adverse event is, conceptualizing it as failure in a care action or in a therapeutic action proposed by workers. Adverse events 
may be either subjective or objective; the latter are the most frequently reported. The following report presents a conception of adverse event relating it to failure in care provided to children:

An adverse event for me is a situation in which a failure occurs, right? Or because it wasn't expected [...]. And let's say, human failure. [...] I see it as an adverse event, whether it is a reaction, intercurrences in care we provide, which leads to an outcome that wasn't expected or situations in which we end up making some mistake (W8).

The processes involving medication were the most evident. Medication errors were confirmed by the workers as those that lead to a great concern similar to the report of the family caregivers/companions. The indiscriminate use of antimicrobials, invasive procedures, handling of medical-hospital material, falls to the ground, characteristics of child growth and development, restrictions in the control of hospital infection, insufficient number of professionals, work overload, deficient and mistaken communication among workers companions and children, and the poor facilities available to accommodate the children's companions were also considered to be adverse events in the view of health workers. Errors in processing medication were the most frequently reported as the following excerpt shows:

[...] Whether it's the wrong dosage, wrong route of administration, the rate at which the medication is administered, for instance, if a medication is administered very rapidly, it may cause respiratory depression, mistaking very similar medications among patients $[\ldots]($ W23).

The subcategory within the fifth category of the actions of health workers in the face of an adverse event indicates the action to be taken if an adverse event occurs. Reporting errors to the health staff was the main conduct listed. The punitive culture is in the process of being abolished and replaced by dialog and guidance provided to workers, showing that the notion of individual failure still predominates over the systemic and procedural conception. Interrupting an adverse event and immediately implementing interventions are actions taken by workers to minimize harm accruing from such errors. Reporting and recording errors together with a collective analysis of their occurrence could be encouraged for the development of a patient safety oriented culture. The following testimony shows the actions adopted by most of the studied workers:

Thank God I've never made a mistake. But I had a very close colleague and I guess it's the worse thing you may experience. I put myself in her shoes... But I guess she did the right thing, which was to realize what she'd done. She wasn't scared, she communicated with the nurse and the physician, which enabled a fast intervention and the adverse event was reversed. [...] we have to support her, tell her she did the right thing $[\ldots]$ (W5)
The second to last category, safe care: strategies used by health workers, presents tactics employed by workers to provide safe care. We note that reviewing and inspecting can be implemented into any sort of action workers might take. Concentration and caution combine with review and inspection to strengthen the practice of safe care. One participant summarizes these strategies well:

Usually, we prevent errors, you know? Whenever I have to prescribe something, I always recalculate many times to make sure there are no mistakes. When I'll administer it, I calculate it again and always review the medication to see the dosage [...] that's why we have to check to see whether the patient is the right one, check the patient's file (W19).

The seventh and last category, for a patient safety oriented culture: educational proposals, was the most complex and difficult because it deals with transformation of and challenges posed to organizations seeking patient safety. Acknowledging and identifying errors was considered the first step toward a patient safety oriented culture, in addition to the fact that an error may be a source of learning. It is essential to deconstruct the notion that such mistakes are individual and expand the focus to the team or collectivity as being co-responsible for the adverse event. Replacing the biomedical model with integral care is seen as an alternative to the development of a safety oriented culture. The conception of collective teamwork was a characteristic identified for the development of a safety oriented culture:

I guess that it is a matter of the entire team being united; the entire staff should evaluate and achieve a consensus, a conclusion. You can always improve, I guess. But it depends on the entire team, because it is a unit where many people work and are responsible for the safety of the unit, of the patient (W7).

There was also a subcategory education for patient safety, which enabled the discussion of strategies and possibilities to implement the subject within the education and qualification of workers. Continuing education in health was indicated as a pedagogical-methodological proposal to (re)orient health workers. Roundtable discussions were mentioned as strategies that could enable the problematization of the subject of patient safety:

It's a new issue, as you said, it's a constant concern. Since it's time to talk about this subject, we have organized roundtable discussions to talk about things, listen to what each has to suggest. An educational alternative would be to promote lectures, show the importance of child safety [...] talking to groups, exchanging experiences $[\ldots]$ (W2).

The subject of patient safety in the curricula of health professions could be discussed as a cross-sectional theme in health care. Certification and quality programs can collaborate to encourage a safety oriented culture within 
the institution through the implementation of guidelines and protocols required by this process. Knowledge production and the use of research addressing patient safety can support the socialization and expansion of the subject in all the contexts of modern society.

\section{Discussion}

Many studies report the incidence of adverse events in the practice of health care internationally(1,9-11). Even though the specificities of studies hinder comparison or replication in multiple contexts, all present similar conclusions related to the prevention of adverse events ${ }^{(9)}$.

It is imperative that workers responsible for the quality of health care provided to hospitalized children reflect upon their praxis, reorganizing their work process, both in individual and collective terms. The development of care provided to children has enabled advancements such as the inclusion of the family, the conception of a child as a social being, the development of health care services and the social sciences, the problematization of child growth and development, among others. The conscientious reception of patients, establishment of bonds, problemsolving capacity, teamwork, and the policing of the humanization of care, are elements that characterize the delivery of integral healthcare, which should guide actions to ensure the protection of hospitalized children ${ }^{(12-13)}$.

Brazilian studies addressing medication errors are those that most stand out in nursing, which is a field taking a leading role in discussions concerning patient safety. However, studies concerning adverse events involving medication address many stages in this process and include in the results other actors such as pharmacists, physicians, pharmacy technicians, and others ${ }^{(14-15)}$. The complexity that involves the medication process, from the writing of a prescription up to its administration, needs to be reviewed by healthcare workers because it is an activity exclusive to them, which requires precision, responsibility and scientific knowledge to avoid such adverse events.

A quasi-experimental study conducted in three pediatric units of a university hospital in the city of São Paulo, Brazil proposes an algorithm that suggests the strategy of promoting seven 'rights' as a methodology to prevent errors. Right Technique and Right Documentation are added to the five rights (Patient, Bed, Drug, Time, Route). The study reported that the incidence of medication errors decreased, though only limited adherence on the part of the nursing staff to the educational proposal was observed(16).

It has been observed over the years that communication among health workers, patients, and families presents many gaps. Among them are the difficulty to dialogue with family caregivers/companions, the excessive use of technical terminology, a lack of records in the patients' files, the attitudes and posture of professionals when questioned by family caregivers, and incomplete and inaccurate, or even omitted, information ${ }^{(17-18)}$.

Many studies have discussed the role of mothers/ family caregivers accompanying hospitalized children and the results coincide with those of this study in which the companion of a hospitalized child receive responsibilities imposed by the nursing staff, which often delegate various activities of its own area of responsibility to the caregiver accompanying the child at the time ${ }^{(17-20)}$. We note that some basic care actions related to providing hygiene or comfort and feeding the child can be shared with the companion as long these activities are monitored, the companions are prepared to perform such activities, and negotiation regarding the care actions is established on a daily basis.

Health institutions should adopt processes and guidelines to promote interdisciplinary work and collaboration ${ }^{(21)}$, which can be determinant in the development of a safety oriented culture. The interdisciplinary work is recommended to advance towards patient safety and quality health care.

Reducing the high prevalence of adverse events arising related to medication and the extension of damage along with the promotion of viable solutions can reduce harm. This is an important and pressing objective for the World Health Organization. Local strategies originating in each institution are encouraged and should be disseminated to reduce the rate of medication-related adverse events ${ }^{(22)}$. The implementation of technological innovations such as intelligent infusion pumps, unitary doses, and bar code readers, among others, contributes to reducing medication errors ${ }^{(23)}$.

Reporting errors is an ethical duty in professions involving human beings. Taking responsibility for a mistake implies ethical conditions in the relationships among the individuals involved because acknowledging and communicating errors represent the autonomy of professionals to act in a responsible and prudent manner. However, the fact errors are going unreported confirms that a punitive culture is still in effect(24).

Re-checking was the $13^{\text {th }}$ step included in the algorithm to prevent medication-related errors in the pediatric field. Additionally, the nurse/staff should check the change-of-shift report for the documentation and records pertaining to the procedures performed(16). This strategy can be adopted in other care situations, especially when performing invasive procedures or interventions.

Systemically approaching errors is a strategy among the most frequently used in institutions that work from 
the perspective of patient safety so that the focus of health workers is part of an enlarged process/system. This procedural view of the adverse event considers the staff, the institution, and patients/family caregivers all to be co-responsible for redesigning the risk management system $^{(1,5,22)}$.

The policy of implementing continuing education brought to attention different actors, enabling all those involved to play a protagonist role in how local health/ education actions are conducted. One study performed in the interior of São Paulo, Brazil shows that roundtable discussions enable the participants to meet and verbalize problems and expose critical weak points concerning the work process, which in turn lead to collective solutions and procedures ${ }^{(25)}$.

The strategy of roundtable discussions can be a way to encourage health workers to talk about errors arising from their professional practice and can be the first step toward the development of a safety oriented culture.

\section{Conclusion}

Therefore, the thesis on which this study is based - care circumstances predispose hospitalized children to adverse events in healthcare settings, which interferes in the safety of patients - is real and complex and requires further research to deepen the subject.

The contextualization and problematization of this thesis enabled us to conclude that care circumstances result from unsafe care processes, which arise from failures in planning, collaboration, performance, evaluation, and monitoring of interventions that go beyond the responsibility of workers involved in the health care provided to children and also beyond care provided by the families. Moreover, it should be a policy involving the health system, and managers in the public and private spheres, to implement a safety oriented culture.

\section{References}

1. World Health Organization (WHO). World Alliance for Patient Safety. Forward Programme 2008-2009. Geneva (SZ): World Health Organization; 2008.

2. World Health Organization (WHO). A World Alliance for Safer Health Care. More Than Words: Conceptual Framework for the International Classification for Patient Safety. Version 1.1. Final Technical Report. Geneva (Switzerland): World Health Organization; 2009.

3. Runciman W, Hibbert P, Thomson R, Schaaf TVD, Sherman $H$, Lewalle $P$. Towards an international classification for patient safety: key concepts and terms. Qual Health Care. 2009;21(1):18-26.
4. Schatkoski AM, Wegner W, Algeri S, Pedro ENR. Safety and protection for hospitalized children: literature review. Rev. Latino-Am. Enfermagem. 2009;17(3):410-6.

5. Jha AK, Prasopa-Plaizier N, Larizgoitia I, Bates DW. Patient safety research: an overview of the global evidence. Qual Saf Health Care. 2010;19:42-7.

6. Wegner W. A segurança do paciente nas circunstâncias de cuidado: prevenção de eventos adversos na hospitalização infantil [tese de doutorado]. Porto Alegre (RS): Escola de Enfermagem da Universidade Federal do Rio Grande do Sul; 2011. 156 p.

7. Yin RK. Estudo de caso: planejamento e métodos. $3^{a}$ ed. Porto Alegre: Bookman; 2005.

8. Minayo MC. O desafio do conhecimento: pesquisa qualitativa em saúde. $10^{\text {a }}$ ed. São Paulo (SP): Hucitec; 2007.

9. Mendes W, Travassos C, Martins M, Noronha J. Revisão dos estudos de avaliação da ocorrência de eventos adversos em hospitais. Rev Bras Epidemiol. 2005;8(4):393-406.

10. Miasso AI, Grou CR, Cassiani SH, Silva AE, Fakih FT. Erros de medicação: tipos, fatores causais e providências tomadas em quatro hospitais brasileiros. Rev Esc Enferm USP. 2006;40(4):524-32.

11. Woods D, Thomas E, Holl J, Altman S, Brennan T. Adverse events and preventable adverse events in children. Pediatrics. 2005;115(1):155-60.

12. Moreira MCN, Macedo AD. O protagonismo da criança no cenário hospitalar: um ensaio sobre estratégias de sociedade. Ciênc Saúde Coletiva. 2009;14(2):645-52.

13. Thomazine AM, Passos RS, Bay OG Júnior, Collet $\mathrm{N}$, Oliveira BRG. Assistência de enfermagem à criança hospitalizada: um resgate histórico. Cienc Cuid Saúde. 2008;7(1):145-52.

14. Cassiani SHB. A segurança do paciente e o paradoxo no uso de medicamentos. Rev Bras Enferm. 2005;58(1):95-9. 15. Miasso AI, Grou CR, Cassiani SH, Silva AE, Fakih FT. Erros de medicação: tipos, fatores causais e providências tomadas em quatro hospitais brasileiros. Rev Esc Enferm USP. 2006;40(4):524-32.

16. Yamanaka TI, Pereira DG, Pedreira MLG, Peterlini MAS. Redesenho de atividades da enfermagem para redução de erros de medicação em pediatria. Rev Bras Enferm. 2007;60(2):190-6.

17. Quirino DDE, Collet N, Neves AFGB. Hospitalização infantil: concepções da enfermagem acerca da mãe acompanhante. Rev Gaucha Enferm. 2010;31(2):300-6. 18. Araujo YB, Collet N, Moura FM, Nóbrega RD. Conhecimento da família acerca da condição crônica na infância. Texto Contexto Enferm. 2009;18(3):498-505.

19. Wegner W, Pedro ENR. Os múltiplos papéis sociais de mulheres cuidadoras-leigas de crianças hospitalizadas. Rev Gaucha Enferm. 2010;31(2):335-42. 
20. Gomes ILV, Caetano R, Jorge MSB. Compreensão das mães sobre a produção do cuidado pela equipe de saúde de um hospital infantil. Rev Bras Enferm. 2010;63(1):84-90.

21. Smith JR, Cole FS. Patient safety: effective interdisciplinary teamwork through simulation and debriefing in the neonatal ICU. Crit Care Nurs Clin N Am. 2009;21:163-79.

22. World Health Organization (WHO). World Alliance for Patient Safety. Patient safety workshop: learning from error. Geneva (SZ): World Health Organization; 2010.

23. Cassiani SHB, Gimenes FRE, Monzani AAS. O uso da tecnologia para a segurança do paciente. Rev Eletr Enferm. 2009;11(2):413-7.

24. Coli RCP, Anjos MF, Pereira LL. The attitudes of nurses from an intensive care unit in the face of errors: an approach in light of bioethics. Rev. Latino-Am. Enfermagem. 2010;18(3):27-33.

25. Carotta F, Kawamura D, Salazar J. Educação permanente em saúde: uma estratégia de gestão para pensar, refletir e construir práticas educativas e processos de trabalhos. Saúde Soc. 2009;18(1):48-51. 